\title{
LAS “IDENTIDADES” DE CHILE EN SUS RELACIONES INTERNACIONALES. ¿ENTRE EL PARADIGMA COMERCIALISTA Y EL TERRITORIALISTA?
}

\section{CHILEAN INTERNATIONAL "IDENTITIES”. BETWEEN TERRITORIAL AND TRADING STATE PATTERNS}

\author{
Miryam Colacrai*
}

RESUMEN

Este trabajo analiza diferentes perspectivas académicas y políticas que reconocen en Chile una "identidad" fuertemente signada por los logros comerciales internacionales. $\mathrm{Su}$ apertura al mundo, factores institucionales y políticos que aseguraron gobernabilidad y continuidad en el diseño de su inserción internacional, lo han diferenciado del "vecindario", es decir, la región a la que suele percibirse como inestable. Esa clara adscripción al paradigma comercialista, sin embargo, no significa que hayan perdido relevancia en su Política Exterior las cuestiones territoriales, por lo cual la identidad chilena se construye entre uno y otro modelo.

PALABRAS CLAVE: CHILE * AMÉRICA LATINA * COMERCIO INTERNACIONAL * ESTADO * ESTADO COMERCIALISTA * ESTADO TERRITORIALISTA * GLOBALIZACIÓN

\section{ABSTRACT}

This article analyzes different scholarly and political perspectives on Chile's new identity, which is strongly based on its commercial success. Its world view, institutional and policy factors that ensure governability and continuity in the course of its international engagement, have made it different than its "neighborhood", that is to say, the region which is sometimes perceived as unstable. It is clear that the adoption of the commercial paradigm does not mean that territorial questions have lost their significance to its foreign policy, rather, there is a Chilean identity constructed between the two models.

KEY WORDS: CHILE * LATIN AMERICA * INTERNATIONAL TRADE * STATE * TRADING STATE * TERRITORIAL STATE * GLOBALIZATION

Investigadora independiente del CONICET.

miryamcolacrai@gmail.com 


\section{INTRODUCCIÓN}

Las modificaciones en el diseño de la economía chilena y en el modo de inserción internacional adoptadas desde los años de Pinochet, marcaron una línea de continuidad y profundización en los años noventa $y$ se proyectaron como una política de estado en los períodos subsiguientes.

Ese devenir implicó para Chile, la asunción de una personalidad o identidad cuyos rasgos se corresponden con los de un Estadocomercialista, según el concepto acuñado por Richard Rosecrance (1986). De allí que la construcción de una inserción chilena exitosa en el mundo globalizado, ha sido traducida en calificativos como: Chile, país diferente, país ganador, país moderno, e incluso país modelo, utilizados por propios y ajenos.

Algunos enfoques académicos y políticos chilenos que se han preocupado por analizar estas ideas y calificativos, sostienen que existe una "versión empresarial de la identidad chilena". Precisamente, ella encuentra asidero en los buenos resultados económicos, en variados ejemplos de su inserción internacional, o ponderando factores institucionales. También ha circulado la percepción de que Chile constituye un país excepcional - comparado con el resto de sus vecinos- es decir, viviendo en un "vecindario inestable".

Otros han criticado esta simplificación de la identidad chilena reconociendo que no hay "una única" visión ni construcción de la identidad que sólo contenga el componente empresarial. Allí se ponen de manifiesto en un amplio arco de posiciones ideológicas y políticas, algunas de las cuales rescatan la necesidad de recuperar una identidad latinoamericana anclada en una fuerte política de inserción en la región; en tanto otras, hacen un reflujo interesante hacia la revalorización de los aspectos territoriales, sobre todo en cuanto a su potencial de recursos naturales (tendencia que también han ido profundizando otros estados, en el nivel regional) $y$ como una necesidad de preservar la seguridad, en su amplio sentido actual.

En cuanto a la impronta del Estado territorialista presente en sus relaciones vecinales, se destacan las dificultades nuevas y viejas en la relación en clave "territorial" con Bolivia y Perú.

La asignación de "cualidad marítima" a Bolivia — como se ha dado en llamar más recientemente a la concesión que pueda hacerse desde Chile - sin que ello signifique otorgarle soberanía, $y$ la disputa que ha ido creciendo en relación con los espacios marítimos con Perú -que condujo a que las autoridades peruanas decidieran presentar la cuestión ante el Tribunal de La Haya ${ }^{1}$ - , constituyen los nudos de la vigencia de una "identidad territorialista".

Resulta particularmente pertinente adscribir a la noción de identidad no definida como una esencia inmutable, que queda suspendida en un pasado remoto - aunque este puede tener su influencia y puede operar, por momentos, retardando los cambios- sino que está sujeta a diversas mutaciones, adaptaciones acorde con las modificaciones propias de la sociedad global y el aporte de la sociedad interna a esas nuevas construcciones.

Desde la perspectiva constructivista, un estado puede poseer múltiples identidades socialmente construidas, aunque la relevancia de identidades singulares y el compromiso que asuman con cada una de ellas variarán atendiendo al contexto en el que se encuentre (Wendt, 1992: 398). Una vez que la estructura se ha institucionalizado puede ser difícil de cambiar, no obstante cabe tener en cuenta que

El Presidente Alan García anunció esta decisión ante el Parlamento el 28 de julio de 2007. De acuerdo con la posición oficial, Perú ha decidido presentar el diferendo ante la Corte Internacional de La Haya, en virtud de que Chile y Perú suscribieron el Tratado Americano de Soluciones Pacíficas (Pacto de Bogotá) de 1948, que establece que si no existe voluntad de las partes, $y$ no habiéndose convenido un procedimiento arbitral, a cualquiera de los Estados-parte le cabe el derecho a recurrir a la Corte Internacional de Justicia, existiendo competencia obligatoria de esta, tratándose de controversias de orden jurídico que versen, entre otras, sobre la interpretación de un tratado y cualquier cuestión de Derecho internacional (artículo XXXI y XXXII del Pacto de Bogotá de 1948, en concordancia con el artículo 36 del Estatuto de la Corte Internacional de Justicia). 
desde el enfoque constructivista "las identidades e intereses, constituidos por los significados colectivos, están siempre en proceso", es decir que dependen para su reproducción de las prácticas de los agentes. Cambiando las prácticas, cambiará el conocimiento intersubjetivo que constituye el sistema ${ }^{2}$.

Realizada esta somera presentación de los ejes más relevantes a partir de los cuales pueden observarse definiciones sobre los modos en que la identidad chilena se conforma, este trabajo considerará rasgos del comportamiento internacional de Chile en el campo de la interdependencia económica - sobre todo lo que sostienen ciertos agentes - $y$ en lo relativo a los aspectos territoriales. En esa dirección, pretende dar cuenta, por un lado, de las diferentes versiones de la "nueva identidad chilena" que acerca $y$ aleja adeptos $y$, por otro lado, realizar un seguimiento y actualización —que aspira a tener continuidad en su análisis futuro- sobre cuestiones territoriales que penden todavía entre Chile y algunos de los países del "vecindario", como son los casos de Bolivia y Perú.

\section{LA "NUEVA IDENTIDAD CHILENA" COMO "RELATO EMPRESARIAL"}

Esta versión, como sostiene el académico Jorge Larrain ${ }^{3}$, es parte de un discurso que se

2 En relación con esto, diversos autores constructivistas han analizado los vínculos entre el Estado y la soberanía, señalando que la identidad de los Estados modernos como soberanos territoriales debe ser entendida como una construcción social, fruto de la interacción y mutuo reconocimiento como tales. Por tanto, ni el Estado ni la soberanía deben ser entendidos como fijos e inmutables (Sodupe, 2003: 179). La soberanía, aunque dada como supuesta, es producto de las prácticas, de las normas compartidas, $y$ se halla sujeta a procesos de reproducción y transformación a través de las prácticas de los estados (Wendt, pp 412-13).

$3 \quad$ Jorge Larraín es Decano de la Facultad de Ciencias Sociales de la Universidad Padre Alberto Hurtado de Chile. Ver más detalles de su análisis sobre Chile en una entrevista realizada por Patricia Peralta Gainza, CLAES, Montevideo, 7 de setiembre de 2005. pretende identitario. $\mathrm{Al}$ intentar conceptualizar la identidad, considera que no es algo que se pueda tener en el puño y decir: esto es la identidad, sino más bien constituye "un conjunto de relatos y puede haber relatos alternativos acerca de la historia de uno, de lo que es uno, un cuento acerca de lo que uno es y hay varios cuentos". Refiriéndose a Chile, considera que en los últimos tiempos ha predominado uno de ellos y es el "relato empresarial".

[Es la] "versión empresarial posmoderna”. [Prosigue diciendo que] ... para ese relato la integración no tiene ningún sentido, $y$ ese relato desgraciadamente es predominante en Chile en este momento, en las esferas directivas, en la política, en el empresariado, en la élite del país. Existe una sensación de que no necesitamos de nadie, que podemos profundizar nuestra integración con el mundo. [Pero, advierte que] esa es una integración de mercado, no es regional, no tiene elementos políticos ni culturales.

Dentro de aquella tendencia que privilegia la visión empresarial podrían inscribirse obras como las de Joaquín Lavin Chile, revolución silenciosa (1987) y Chile, sociedad emergente (1989). En ellos se trazan las ideas-fuerza de ese nuevo rumbo adoptado por ciertas élites chilenas que identifican la modernidad y el progreso unidos simbióticamente con al paradigma neoliberal y con la adscripción acrítica a la globalización.

El modo en que esta nueva personalidad fue exhibida ante el mundo tiene, según Larrain (2001:162-163), un ejemplo de enorme contenido simbólico en la presentación chilena del "iceberg" en la Expo' 92 de Sevilla. Allí se ponía en exhibición la idea de Chile país diferente, país ganador, país modelo ${ }^{4}$. De ese modo se conjugaron tres

4 Conviene señalar que la obra mencionada da cuenta, en parte, de los resultados de investigación que llevó adelante conjuntamente con Jorge Vergara "Identidad cultural y crisis de modernidad en América Latina, el caso de Chile". Estudios de base de la investigación FONDECYT nro. 1960050 (Santiago, Universidad Alberto Hurtado, 1998). 
matrices identitarias, si nos atenemos a las palabras de Bernardo Subercaseux. La primera idea marca la diferencia con el resto de América Latina, presentando un país de trazos fríos y europeos, lejos de tropicalismos; la segunda matriz estaba basada en los "éxitos o ganancias" económicos, con una actitud dinámica y "triunfalista”, y la tercera, mostraba un país eficiente con un desarrollo acelerado.

Estas tres matrices tenían como elemento común el sustrato económico y tecnocrático que experimenta la modernización chilena. Este nuevo discurso tiene implícita una nueva concepción cultural que destaca "el empuje, el dinamismo y el éxito" y a partir de ello, establece distancias "conceptuales" con gran parte de los países vecinos.

\section{EL DESARROLLO DE UNA "POLÍTICA DE ESTADO" ALREDEDOR DE LA CUESTIÓN DE LA INSERCIÓN DE CHILE EN LA ECONOMÍA GLOBAL}

Un signo característico de las últimas décadas, es que Chile ha mantenido una fuerte continuidad en su política exterior, donde se realzan el estrechamiento y multiplicación de sus relaciones comerciales, a través de la firma de acuerdos de asociación y libre comercio sobre la base de la apertura económica. Una fuerte $y$ diversificada diplomacia comercial, una inserción económica anclada en el regionalismo abierto, que ha gozado de una importante dosis de autonomía en relación con la variable política, ha mostrado ser el hilo conductor o la columna vertebral de su política exterior.

El diseño de la política exterior chilena en tiempos del presidente Lagos, como sostuvo el mandatario, propendió a la inserción internacional de Chile. Así sostenía —en diferentes párrafos del discurso inaugural de las sesiones legislativas de su último año de gobierno:

No hemos descansado un instante en abrirle un mayor espacio a Chile en este mundo global. Chile ha conquistado la más expectable posición económica de su historia. Nuestra tarea es asegurar que ese impulso no se frustre. Si mantenemos firme las orientaciones que traemos, estoy seguro que daremos el gran salto al desarrollo. ¡Chile tiene que aprovechar las oportunidades magníficas que se abren gracias a nuestra inserción en el mundo que hemos conquistado! ${ }^{5}$

La continuidad y profundización de esta tendencia también es evidente durante el gobierno de Michelle Bachelet, ya que a los Tratados de Libre Comercio existentes, se sumaron nuevos acuerdos que abren puertas en la región Asia-Pacífico, sin perder la posibilidad de firmar otros que le permiten tener socios en el espacio latinoamericano ${ }^{6}$.

\section{LA "NUEVA IDENTIDAD CHILENA", ¿FACTOR DE ALEJAMIENTO DE AMÉRICA LATINA?}

Cierta sensación de que Chile, a la vez que desplegaba todo su empuje y se insertaba en el competitivo mundo económico actual, iba alejándose de su área "natural" geográfica, fue el motivo de diversos debates y bastante escritura académica y política. Líderes de opinión latinoamericana tomaron como tema de sus notas la distancia o aislamiento de Chile con relación a sus vecinos y sorprendió también que desde el New York Times se mencionara a Chile como el "niño rico de la cuadra que comienza a sentirse solo"?.

$5 \quad$ Mensaje presidencial ante el Congreso Nacional en el inicio de la legislatura ordinaria, 21 de mayo de 2004.

6 Dichos Acuerdos comprenden a Canadá (1996), Acuerdo de Asociación con MERCoSUR (Argentina, Brasil, Uruguay, Paraguay) (1996), México (1998), Centroamérica (Costa Rica, El Salvador, Guatemala, Honduras, Nicaragua) (1999), Comunidad Europea (2002), Corea del Sur (2002), Estados Unidos (2003), Asociación Europea de Libre Comercio AELC (2003), República Popular China (2005, ratificado 2006); Nueva Zelanda-Singapur-Brunei (2005), Colombia (2006), Panamá (2006), Perú (2006), Japón (2007) y Australia 2008. Recientemente, se han dado pasos para un TLC con Uruguay que podría concretarse en 2009.

7 Ver comentarios en Carolina García Huidobro, "Chile y Latinoamérica. Los vecinos toman distancia”. En Revista Universitaria 84, 2004, pp.10-13. 
Al respecto, la Universidad Católica de Chile (Santiago) organizó en el 2004 un foro para discutir desde la óptica política, económica e histórica esta "supuesta" tendencia al aislamiento chileno en relación con Latinoamérica, el cual contó con la participación de Rosendo Fraga (por Argentina), el economista y consejero del Banco Central de Chile, Jorge Desormeaux y el historiador Joaquin Fermandois ${ }^{8}$. Refiriéndose a la Argentina, Fraga recogió la opinión resultante de una encuesta realizada en marzo - justo antes de desatarse la crisis del gas - y remarcó que la imagen de popularidad de Chile había arrojado una cifra del 44\%, mientras en similar sondeo tres años antes la imagen positiva de Chile apenas llegaba a $16 \%$. Por su parte, Desormeaux ${ }^{9}$ hizo suya la percepción de cierta "hostilidad" de los vecinos hacia Chile y consideró que "estas señales representan el costo menor que el país debe pagar por sus buenos resultados económicos $y$ por integrarse al mundo globalizado $y$ desarrollado". Agregaba que "el sentimiento de aislamiento de Chile es, en buena medida, el reflejo de una insatisfacción que se origina en las profundas diferencias en materia de resultados económicos que exhibe América Latina en los últimos 20 años". Y, entonces, "Chile es culpable de haber sido exitoso". Por su parte, la exposición de Fermandois, en un tono más ecléctico, abordó el tema desde una perspectiva histórica y, afirmó que "Chile ha vivido durante las dos últimas décadas su mejor período histórico del siglo Xx aunque reconoció que el modelo chileno aún tiene aspectos perfectibles, no ha creado todavía las condiciones de "un país desarrollado".

8

Ibídem.

$9 \quad$ Más detalles del pensamiento de Desormeaux pueden consultarse en "Tres décadas de reformas en Chile: Algunas lecciones: ¿Por qué ha sido Chile más exitoso que los otros países de América Latina?", Conferencia dictada durante el XIII Ciclo de Jornadas Económicas, celebradas en junio de 2004, en el auditorio del Banco de Guatemala. Ver <www.banguat.gob.gt/publica/ banca/049200501/003.pdf>
Desde el Centro para la Apertura y el Desarrollo de América Latina (CADAL ${ }^{10}$ ) también se marcó una línea divisoria entre la América Latina estancada, atrasada, no integrada al mundo y el "Chile que juega el juego de la inserción competitiva en el nivel internacional", no le teme a la globalización y aprovecha sus oportunidades. Así se sostiene que

... en una región fundamentalmente estancada, Chile se destaca por un dinamismo económico que en muchos aspectos lo ubica entre los punteros globales del desarrollo. En ese contexto, Mauricio Rojas afirma que la diferencia tan abismal que se da con el resto de la región, se debe a tres componentes esenciales: un capitalismo moderno y abierto al mundo; un sistema institucional sólido y confiable; $y$ un amplio consenso político sobre el valor de la estabilidad y la plena incorporación de Chile a la globalización. El nuevo sistema institucional fue básicamente construido durante los años 80 y hábilmente consolidado por los regímenes democráticos, aunque recoge una importante herencia del viejo Chile, un inestimable legado de un país que tempranamente se alejó del caudillismo y supo construir un aparato de Estado decente. En esto Chile está lejos del resto de la región, donde la política es todavía la lucha por la repartija y la corrupción, el pan de cada día ${ }^{11}$.

En orden a dar algún tipo de respuestas al debate sobre la prioridad que tiene América Latina para la Política Exterior chilena o el alejamiento chileno respecto de la región y evitar lo que se ha considerado un "exceso de

10 Tiene su sede central en Buenos Aires, con vínculos fuertes en el resto de América Latina.

11 Ver Rojas, Mauricio, "Chile y la globalización", $<$ www.cadal.org > El autor es historiador económico y miembro del Parlamento de Suecia. Ha escrito Mitos del milenio. El fin del trabajo y los nuevos profetas del Apocalipsis, CADAL/Timbro, 2004. 
polarización", un trabajo presentado por FLACSO (Chile) en $2005^{12}$, bajo el elocuente título: ¿Good Bye! América Latina? (sic) intenta presentar como inadecuado que la inserción de Chile en el mundo implique un "juego de suma cero". Ello se sustenta en varias razones: Primero, porque la naturaleza de las relaciones con otras regiones del mundo y América Latina, son de distinto orden y se complementan. Segundo, un mayor acercamiento con otras regiones del mundo (China, Europa, Estados Unidos) podría llegar a tener efectos de suma positiva con el resto de la región, $y$ de ese modo, podría Chile constituirse efectivamente "en plataforma" 13 . Por ello, sus autores analizan una serie de mitos relativos al "alejamiento" de Chile con respecto a la región y remarcan que la pregunta central a resolver no debiera ser cuáles son las "prioridades" regionales, sino cómo Chile, en y desde - junto con la región- pueden aprovechar las ventajas que ofrece un contexto de globalización y apertura y minimizar los riesgos que ello trae. Reconocen que Chile enfrentará un desafío de política exterior de gran magnitud para la próxima década por el contexto de inserción regional que ha venido experimentando en los últimos años. En primer lugar, existen altos niveles de disparidad en términos de desarrollo y estabilidad político-social al interior de la región; en segundo lugar, Chile avanza en un escenario de interdependencia compleja, lo que implica mayores niveles de interrelación global $y$ regional $y$, finalmente, debe tenerse presente que subsisten problemas derivados de la "herencia histórica" de relaciones vecinales, particularmente en la frontera norte del país. Chile, en este sentido, debiera asumir un rol estabilizador de América del Sur, promoviendo el comercio y la resolución de conflictos por medios pacíficos.

12 Ver Claudia Fuentes y Claudio Fuentes Saavedra (Director de FLACSO, Chile), consultado en $<$ bibliotecavirtual.clacso.org.ar/ar/libros/chile/ flacso/good.pdf>

13 Dicha expresión podría leerse, por ejemplo en el campo de las excelentes relaciones chilenas con la región de Asia-Pacífico, como "país puente" para otros países del Cono Sur considerados individualmente o en el esquema del MERCOSUR.
En un sentido similar, se pronuncia Arturo Valenzuela quien reconoce que "Chile es el país probablemente más globalizado de América del Sur, lo ha hecho muy bien en cuanto a su proyección internacional. Pero tampoco puede descuidar su vecindario". Y concluye que una agenda de futuro no consiste en tratar de separarse de América Latina, sino en ayudar a que toda la región alcance mejores niveles de integración y desarrollo ${ }^{14}$.

En suma, podría concluirse que, excepto aquellos que tienen una posición crítica respecto de la globalización y no adscriben a ella como una "esencia" de la nueva identidad chilena, existe un variado arco político que -aunque con matices - identifica importantes logros en la economía chilena desde los noventa. Pueden señalarse como los más relevantes un favorable cambio estructural en sus cuentas externas con aumentos en los flujos de inversión externa, incremento $y$ diversificación en las exportaciones, elevada acumulación de reservas internacionales, reducción drástica en los indicadores de endeudamiento y de riesgo país. De allí que tiendan a considerar como pilares del éxito chileno de las últimas décadas, además del ejercicio de un capitalismo moderno y abierto al mundo; un sistema institucional sólido y confiable; $y$ un amplio consenso político sobre el valor de la estabilidad y la buena gestión así como también, la madurez de la clase política chilena.

\section{LAS RELACIONES DE CHILE CON EL "VECINDARIO"}

Suele sostenerse que, por distintas razones, las relaciones de Chile con los países del "vecindario" no son las mejores. De todos modos, hay situaciones diferenciadas que convendría remarcar. Así aparecerían, por un lado, lo ocurrido desde 1990 con la Argentina que se ha transformado en una relación estratégica caracterizada por el pragmatismo $y$, con proyecciones hacia la conformación de una asociación

14

Ver Claudia Heiss, "Arturo Valenzuela y la encrucijada de la Política Exterior Chilena”. En: El Diario Financiero, 13/4/2006. 
política. Por el otro, la persistente retórica "territorialista" dentro de la cual se enmarca —en gran medida - las relaciones de Chile con Bolivia y Perú.

\subsection{UN RÁPIDO RECORRIDO POR LOS AVANCES EN LA RELACIÓN CON LA ARGENTINA. CREACIÓN DELIBERADA Y SOSTENIDA DE MÁS INTERDEPENDENCIA ${ }^{15}$}

Poco antes de las elecciones presidenciales que llevarían a Michelle Bachelet a la primera magistratura de Chile, en su visita a la Argentina en octubre de 2005, señalaba contundentemente que:

Argentina y Chile transformaron su relación en un sentido estratégico desde el conflicto a la cooperación y hacia la asociación política, actualmente en construcción. Creo que este cambio llegó para quedarse, porque ha sido construido durante una década y media y está incorporado como política de Estado en ambos lados de la cordillera ${ }^{16}$.

Una vez electa, reiteró la prioridad que asignaría su gobierno a la relación con la Argentina, con quien reforzaría los lazos en su intento por acercarse a la región y confirmó que uno de sus primeros viajes sería a Buenos Aires $^{17}$.

Sólo a modo de recorrido panorámico -ya que el foco de interés en este trabajo es dar cuenta de "cuestiones pendientes" que Chile

15 En otros trabajos se ha abordado en detalle la evolución positiva de la relación argentino-chilena y de modo específico, la solución de diferendos limítrofes. Ver Colacrai, Miryam. "La Política Exterior Argentina hacia los vecinos durante los 90", en $<w w w . c e m a . e d u . a r / c e i e g / c o l a c r a i . p d f>$

16 Entrevista: "El nivel en la relación entre Chile y Argentina llegó para quedarse". En Diario Clarín, Buenos Aires, el 5 de octubre de 2005.

17 Declaraciones en rueda de Prensa con periodistas extranjeros. Diario La Nación, Buenos Aires, 17 de enero de 2006. tiene con países limítrofes - pueden señalarse algunos de los hechos que permitieron la continuidad en la creación de "interdependencia" con la Argentina.

El 21 de marzo de 2006, la presidenta Bachelet $y$ el presidente Kirchner firmaban en Buenos Aires una Declaración Conjunta, precedida por una Declaración de Principios que reimpulsaba el vínculo estratégico en el nivel regional y multilateral, la cuestión de los derechos humanos, la continuidad de la Política de Estado de integración de sus gobiernos. La declaración también se refirió al alto nivel de integración que Argentina y Chile han alcanzado entre sus Fuerzas Armadas. Acordaron, también, convertir los Comités de Frontera en Comités de Integración y resaltaron el dinamismo creciente del comercio bilateral $y$ del flujo continuo y dinámico de las inversiones, la importancia del comercio bilateral como también "el trabajo desarrollado por el Grupo Bilateral Ad-hoc sobre Asuntos Energéticos y dispusieron la continuidad de sus labores con el objetivo de enfrentar de la mejor manera los problemas de suministro de gas ${ }^{18}$. Entre los aspectos puntuales, se remarcó la decisión de ambos países de llamar a licitación internacional para la rehabilitación por iniciativa privada del Ferrocarril Trasandino Central, y avanzar en otros importantes estudios y proyectos de conectividad, como el paso fronterizo Agua Negra, Paso Pehuenche, Río Turbio-Puerto Natales el proyecto del Ferrocarril Bioceánico Transpatagónico, concluir las obras de infraestructura en Tierra del Fuego, todos ellos considerados importantes para la integración.

Asimismo dieron mandato a los respectivos ministros para elaborar un programa de trabajo 2006-2010 que permita llegar al Bicentenario con proyectos conjuntos. A todo ello se suma, además de lo actuado en los

Declaración de Principios y Líneas de Acción Conjunta Argentina-Chile, Buenos Aires, 21 de marzo de 2006. Posteriormente, el 5 de abril de 2006, los Gobiernos de Chile y Argentina suscribieron el Acuerdo mediante el cual los Comités de Frontera constituidos en el marco del Acuerdo de 1997, se denominarán "Comités de Integración", manteniendo las facultades allí establecidas. 
Comités de Integración, el avance sostenido de las relaciones subnacionales, comprendiendo tanto regiones $y$ provincias como localidades vecinas $y$ acercamientos entre ciudades no necesariamente limítrofes.

Esta relación vecinal que es "pragmática" $y$ se ha sostenido en el tiempo desde los años 90 , no es asimilable a la que se da con los otros actores del "vecindario" en los temas relativos a la "variable territorial".

\section{2. DIFICULTADES NUEVAS Y VIEJAS EN LA RELACIÓN “TERRITORIAL” CON BOLIVIA Y PERÚ}

En la caracterización de la relación bilateral $y-a$ la vez- de la identificación frente al "otro", las cuestiones territoriales que entrelazan a Chile, Bolivia y Perú continúan conformando un área de cuestiones a las cuales hay que prestarle importancia. En este sentido, si bien no haremos un análisis pormenorizado de la evolución histórica, es necesario relevar el estado de la "cuestión" en la actualidad entendiendo que este es el resultado de acuerdos y desacuerdos que vienen de larga data ${ }^{19}$.

De modo sintético, Luis Maira se refiere a ambas cuestiones en un artículo publicado en Foreign Affairs en español, en cuyo texto recuerda que:

La amplia victoria que Chile obtuvo frente a Perú (que incluyó la ocupación de Lima hasta 1884) dio lugar a dos acuerdos provisionales de término de la guerra, suscritos por separado con Perú y Bolivia. Mediante ellos, tomó control de la provincia de Tarapacá de propiedad del Perú y, al sur de esta, de la provincia de Antofagasta $y$ del litoral boliviano. En el

Asimismo estos constituyen casos de estudio que requieren un análisis a futuro, sobre todo con el propósito de relevar la evolución de los mismos, su eventual resolución o las dificultades para arribar a un acuerdo, $y$ de ese modo poder contar con mayor evidencia empírica para determinar la existencia de patrones de vinculación diferente si se los compara con la "construcción" de la relación bilateral con la Argentina. caso de Perú (Tratado de Ancón, de 1883) quedó pendiente el dominio definitivo de las ciudades de Tacna y Arica. Las etapas de 1884 a 1904 con Bolivia, y de 1883 a 1929 con Perú, fueron de intensas negociaciones y propuestas entre los tres países. Los tratados de 1904 y 1929 establecieron la certeza del dominio para cada una de las partes $y$, en términos jurídicos, cerraron el diferendo, quedando solamente pendientes otras compensaciones y el pago de los ajustes complementarios. En cuanto a Bolivia, Chile obtuvo en el tratado de 1904 la cesión definitiva $y$ a perpetuidad del litoral situado al sur de los antiguos dominios peruanos. Para compensar la mediterraneidad, se estableció un acuerdo amplio de libre tránsito de bienes y mercaderías bolivianos por cualquiera de los puertos chilenos del norte. Chile asumió la construcción de un ferrocarril entre Arica y La Paz y el pago de una compensación monetaria. Las diferencias con Perú se resolvieron sin realizar el referendo que las partes habían acordado en un plazo de 10 años, con la devolución definitiva de Tacna a Perú y la conservación de Arica bajo control chileno. Durante el último siglo se ha planteado sobre ese piso jurídico la reclamación boliviana de un puerto soberano en el Pacífico... ${ }^{20}$

Bolivia perdió su litoral marítimo en la Guerra del Pacífico y no ha cesado de reclamar su acceso al mar, atribuyendo gran parte de su atraso económico, precisamente a no contar con puertos marítimos propios para el desarrollo de su comercio exterior. La "mediterraneidad de Bolivia" ha sido un argumento de peso en la mayor parte de las negociaciones con otros países limítrofes - incluida la Argentina- para la obtención de algunas Zonas Francas.

20 Maira, Luis, "Las relaciones entre Chile y Bolivia en el centenario del tratado de 1904". En Foreign Affairs En Español, octubre-diciembre 2004, Vol. 4, nro. 4, pp.94 
Chile y Bolivia tienen suspendidas sus relaciones diplomáticas desde 1978, cuando fracasó un acuerdo entre los entonces presidentes de facto Augusto Pinochet $y$ Hugo Banzer para dar a Bolivia un corredor terrestre al Pacífico debido al veto del Perú, cuyo gobierno no aceptó un trazado entre el puerto chileno de Arica y la línea de la Concordia. Desde entonces, los dos países mantienen relaciones diplomáticas limitadas en el nivel de consulado ${ }^{21}$, habiéndose producido algunos acercamientos para intentar llevar a la mesa de negociaciones cuestiones políticas y económicas, entre las cuales se destacan el primer contacto entre Cancilleres, a iniciativa del Ministro Insulza (Chile) en noviembre de 1997, en el marco de la Cumbre Iberoamericana, celebrada en Margarita (Venezuela). Un segundo paso, lo constituye el Comunicado Conjunto firmado en Algarbe (Portugal) el 22 de febrero de 2002 por los Cancilleres Murillo y Valdez bajo la premisa de que las cuestiones para conformar una agenda de trabajo y negociación "tomarían todos los temas de interés para las partes, sin exclusiones" 22 .

Los vínculos consulares y comerciales de Chile y Bolivia debieron enfrentar una nueva crisis - significativa, por cierto- desde octubre de 2003. En esos momentos, el peso de la resistencia popular boliviana a que se llevara adelante una negociación del gobierno de Gonzalo Sánchez

21 Después del conflicto de 1879, Bolivia mantuvo relaciones diplomáticas con Chile desde 1890 hasta 1962, año en que rompió las relaciones unilateralmente. Se reanudaron en 1975, con el Acuerdo de Charaña, firmado por Hugo Banzer y Augusto Pinochet. La suspensión de las relaciones diplomáticas desde 1978, hace que sólo se mantengan entre ambos países vínculos en su nivel consular. Chile posee Consulados Generales en las ciudades de La Paz y Santa Cruz, una oficina comercial en La Paz y un Consulado Honorario en Cochabamba. Bolivia por su parte, tiene representaciones a través de Consulados Generales en Santiago y en Arica, y consulados en Antofagasta, Calama e Iquique. Además mantiene un Consulado Honorario en Valparaíso y una oficina comercial en Santiago.

Un importante aporte a la historia comparada aparece en Maira, Luis (Chile); Murillo De La Rocha (Bolivia), El largo conflicto entre Chile $y$ Bolivia. Dos visiones. Aguilar Chilena de Ediciones, Santiago de Chile, 2004. de Lozada para un puerto de exportación de gas natural por el litoral chileno, entre los motivos más relevantes, condujeron a la dimisión del presidente boliviano ${ }^{23}$.

Fue especialmente grave la denominada “crisis del gas" del año 2004, momento en que se cumplía el centenario del Tratado de Paz y Amistad entre Chile-Bolivia de 1904, que derivó en una secuencia de levantamientos sociales, bloqueos en zonas limítrofes, actos de violencia y represión en la que hubo que lamentar muertes de civiles. La propuesta de "gas por mar" tiene por origen el referéndum realizado por el gobierno de Carlos Mesa el 18 de julio de 2004, que consultó a la población sobre la posibilidad de utilizar el gas como un mecanismo más en las conversaciones con Chile sobre la demanda de reintegración marítima.

Las relaciones chileno-bolivianas, amén de las dificultades ocasionadas por la discontinuidad institucional boliviana, son el reflejo de una historia de desencuentros, de la persistencia de otras cuestiones no resueltas como las relativas a las aguas del Silala, $y$ de percepciones diferentes sobre el nudo de la cuestión que los enfrenta. Salida al mar, soberanía sobre litoral marítimo, "mediterraneidad de Bolivia", condición de "estado enclaustrado", asignación de cualidad marítima sin soberanía, son semánticamente cosas diferentes que también conllevan a efectos jurídico-políticos diferentes ${ }^{24}$.

23 Durante 2001, había trascendido que Chile podría entregar en comodato $82 \mathrm{~km}$ de su costa norte a cambio del suministro de gas boliviano, arreglo que se extendería por 99 años y comprendería a un sector entre los puertos de Mejillones y Cobija (al norte de la ciudad de Antofagasta). El proyecto implicaría la construcción de un gasoducto entre Tarija y la costa chilena, que permitiría a Bolivia exportar este combustible al mercado de la costa oeste de Estados Unidos.

24 Una encuesta realizada por La Tercera a fines de marzo de 2006, justo después de la visita de Evo Morales para la asunción de Michelle Bachelet al poder, mostró que el $62 \%$ de los chilenos estaría en contra de una cesión de franja territorial con soberanía a cambio de una compensación territorial. Aunque un $90 \%$ de los encuestados se manifestó a favor de restablecer relaciones diplomáticas entre ambos países y que un $75 \%$ estaba de acuerdo con 
Aunque ciertos gestos de acercamiento se avizoran desde las presidencias de Evo Morales (Bolivia) y de Michelle Bachelet (Chile) durante 2006, la gran sensibilidad que envuelve a esta relación, estimula dudas respecto de que puedan producirse avances esenciales. Precisamente la fórmula mar x gas, contiene en sus términos los dos factores que, en cada uno de los casos, contribuyen fuertemente al diseño de sus respectivas identidades. Esto es, la disputa boliviana por su salida al mar es un objetivo que constituye un "modo de ser y de ver su política exterior", en tanto que para Chile, si tomamos en cuenta la construcción presente de una identidad anclada en la visión del estado-comercialista, el no contar con ese recurso energético estratégico para alimentar su propio crecimiento económico -téngase presente que la matriz energético chilena es gas-dependiente- lo coloca en una situación de gran vulnerabilidad.

El caso de la disputa con Perú, se refiere a una zona marítima de aproximadamente 37000 km² en el Océano Pacífico. Para Chile no existen temas limítrofes pendientes con el Perú, ya que los límites marítimos han sido definidos en 1952 y 1954 cuando ambos países suscribieron Convenios de pesca donde se especificaban claramente las fronteras marítimas.

Para Perú, en cambio, el límite marítimo con Chile no está definido ya que nunca se ha firmado un Tratado que establezca dicho límite. Es en ese sentido que se sostiene que en el Tratado de Ancón (1883), así como en el complementario Tratado de Lima de 1929 se determinaron las nuevas fronteras terrestres, pero no existen referencias sobre las fronteras marítimas entre ambos países.

buscar soluciones para la aspiración marítima boliviana sin cesión de soberanía, un $69 \%$ se opuso en caso de discutir temas de soberanía. Además, un $88 \%$ de los encuestados señaló que, en caso de que existiese un acuerdo, debía ser aprobado por un plebiscito. Sin embargo, en una consulta realizada por la municipalidad de Arica, la población se opuso ampliamente a entregar una salida a Bolivia por esa zona, el alcalde entonces viajó a Santiago para entregar los resultados en La Moneda, para que el gobierno tuviera en consideración la opinión local de los ariqueños. Ver <kaleidoskopios. googlegroups.com/web/pablo.villoch.bolivia.pdf>
Desde Chile se estudian argumentaciones jurídicas que, recorriendo no sólo el Tratado de 1929 sino, también, las respectivas declaraciones de 200 millas, una Ley de Petróleo promulgada por Perú en 1952, los textos de la Declaración de Santiago de 1952 (recuérdese que creó la Comisión Pesquera del Pacífico Sur-CPPS) y la Convención sobre Zona Especial Marítima de 1954, sumados a otros antecedentes conforme a las tareas realizadas por la Comisión Mixta en 1968 y 1969, apuntan a demostrar que no existen cuestiones pendientes $^{25}$. Según la posición chilena, los acuerdos de 1952 y 1954 tienen la naturaleza de un Tratado Internacional, se basan para ello en la Convención de Viena de 1980, que si bien no tiene efectos retroactivos, están reconociendo un derecho internacional consuetudinario.

En marzo de 2004, Perú reclama como un tema pendiente la frontera marítima entre ambos países. Se señala que la línea divisoria debe ser equidistante $y$ no recta, lo que haría ganar a ese país más de 30 mil kilómetros cuadrados de mar. Perú envió a Chile una nota diplomática donde solicita, el 19 de julio de 2004, iniciar negociaciones sobre el tema en cuestión, $y$ Chile en respuesta casi inmediata, señaló que no procede el pedido peruano porque no hay ningún tema pendiente entre ambos países. Al respecto la Canciller Soledad Alvear reafirmó la vigencia de los límites marítimos con Perú, recordó que hay tratados que datan de cincuenta años, los cuales están perfectamente en vigencia y agregó que en 1968 y 1969 el límite marítimo fue objeto "de un trabajo en terreno acordado por los dos países" 26 .

Estos cruces de declaraciones de tono diverso se producen a pocos días de una gira

25 Cruz Jaramillo, Jorge; Sandoval Santana, Roberto, "Consideraciones en torno al límite marítimo Chile-Perú". En: <www.revistamarina. cl/revistas//2002/6/cruz-sandoval-pdf > Consultado 6 de julio de 2004 .

26 Ver al respecto El Mercurio, 16 de septiembre de 2004. Un análisis histórico y de los acontecimientos presentes puede hallarse en Milet, Paz Verónica: "Chile-Perú: las dos caras de un espejo". En Revista de Ciencia Política, Pontificia Universidad Católica de Chile, Volumen XXIV, nro. 2, 2004. 
de la Canciller chilena que contemplaba visitar Lima, la cual debió ser cancelada.

La situación, lejos de mejorarse, luego de la finalización de la administración Lagos ha ido escalando y hay una firme decisión de Perú - sobre la cual trabajan sus técnicos y diplomáticos- de que la cuestión sea presentada ante la Corte Internacional de Justicia.

La presidenta Bachelet ha sostenido reiteradamente que su país mantendrá una actitud de firmeza ante el planteo peruano, dado que este apuntaría a modificar lo que Santiago considera límites marítimos definitivos entre los dos países. "Perú intenta desconocer en forma unilateral y por primera vez en la historia la jurisdicción que Chile ha ejercido, ejerce y ejercerá en la frontera terrestre y marítima". Serenidad, pero firmeza a la vez, resumen la actitud que el gobierno chileno manifiesta que sostendrá con respecto a esta cuestión.

El rápido recorrido sobre dos de las cuestiones que se leen en clave territorialista en la Política Exterior de Chile, permiten reflexionar acerca de la existencia de cuestiones de soberanía y seguridad del estado que no quedan subsumidas ni anuladas por la preeminencia que tiene el modelo de inserción internacional concebido a imagen del Estadocomercialista. Más aún algunos estudios, al evaluar la Política Exterior chilena estiman que uno de los errores de percepción fue no reparar en los factores geopolíticos, por considerarlos anacrónicos y conflictivos ${ }^{27}$. De allí desprenden que, con relación a los países vecinos, la diplomacia económica se verá, en el corto plazo, sorprendida por tres situaciones que dan cuenta de su error:

$\diamond$ La salida al mar para Bolivia es más importante que concretar un ventajoso negocio de exportación del gas.

४ La redelimitación de la frontera marítima por parte de Perú, obedece a su interés

Mendoza, Juan Eduardo. "Las crisis de gobernabilidad y los conflictos vecinales desde la perspectiva de la seguridad y defensa: 2000-2006". (Tesis de Maestría). Pontificia Universidad Católica de Chile, Magíster en Ciencia Política, Mención Estudios de Defensa publicada en Estudios de Defensa nro. 18, pp.13-14. geopolítico de proyectarse sobre el norte chileno y mantener una influencia sobre el puerto de Arica.

$\diamond$ El apoyo de Chile a Gran Bretaña durante la guerra de las Malvinas no es un tema del pasado histórico de Argentina, sino que está muy vigente.

\section{ALGUNAS REFLEXIONES FINALES}

Este trabajo ha procurado analizar, a partir de diferentes referentes académicos y políticos, el itinerario recorrido por Chile, particularmente en las últimas dos décadas, que lo ha llevado a constituirse en uno de los países de la región latinoamericana $y$, especialmente sudamericana, con mayores proyecciones en la economía globalizada. Una combinación de apertura al mundo, factores institucionales $y$ políticos que aseguraron gobernabilidad $y$ continuidad en el diseño de su inserción internacional, lo han diferenciado de un "vecindario" al cual se ha considerado inestable.

En cierto modo, estas tendencias de jugar de modo creciente el "juego de la interdependencia" iniciada durante el gobierno autoritario del General Augusto Pinochet, fueron ampliamente sostenidas y profundizadas en la década del noventa, siendo Chile prácticamente el único país de la región que pudo sacar ventaja económica de la bonanza de esos años. La continuidad observada en el modelo de inserción internacional contribuye a hallar rasgos fuertemente identificados con la imagen del Estado-comercialista.

Hemos discutido, también, algunos impactos que esta inserción internacional contribuyó a instalar en el resto de la "comunidad regional", dando cuenta tanto de aquella percepción sobre un alejamiento o aislamiento chileno de su entorno más próximo, como así también de la construcción de un mito alrededor de ello.

Finalmente, $y$ casi haciendo un recorrido panorámico, tomamos en consideración algunas de las cuestiones territoriales que constituyen parte de la agenda negativa que Chile mantiene con sus vecinos, particularmente con Bolivia y Perú. 
Los temas que quedan comprendidos en esos diferendos, además de tener un basamento geopolítico que no es ajeno al diseño de la Política Exterior chilena, dejan al descubierto - como en el caso del gas - cierta vulnerabilidad sectorial que puede impactar el normal desarrollo del modelo económico que Chile viene aplicando exitosamente $y$ que le ha permitido ventajas en el comercio internacional durante casi tres décadas.

Como colofón de las consideraciones presentadas en este trabajo y reconociendo que ellas constituyen un enfoque preliminar y que las mismas tienen final abierto, es necesario dejar planteado el interés por continuar profundizando esta dinámica, a la luz de nuevos acontecimientos de la agenda económica internacional $y$ de la propia agenda regional.

\section{BIBLIOGRAFÍA}

Colacrai, Miryam. La politica exterior argentina hacia los vecinos durante los 90. En: $<w w w . c e m a . e d u . a r / c e i e g / c o l a c r a i ~ p d f>$

Cruz Jaramillo, Jorge; Sandoval Santana, Roberto. Consideraciones en torno al límite marítimo Chile-Perú. En: <www.revistamarina. cl/revistas//2002/6/cruz-sandoval-pdf> [Consultado 6 de julio de 2004].

Fuentes, Claudia; Fuentes Saavedra, Claudio. “¿Good Bye! América Latina?”. La gobernabilidad en América Latina. Balance reciente y tendencias a futuro. FLACSO, Secretaria General. En: <bibliotecavirtual. clacso.org.ar/ar/libros/chile/flacso/good. pdf $>$ [Consultado 6 de marzo de 2007].

Lavin, Joaquín. Chile, revolución silenciosa. Santiago de Chile: Editora Zig-Zag, 1987.

Lavin, Joaquín. Chile, sociedad emergente. Santiago de Chile: Editora Zig-Zag, 1989.
Larrain, Jorge. Identidad chilena. Santiago de Chile: Lom Ediciones, 2001.

Maira, Luis. "Las relaciones entre Chile y Bolivia en el centenario del Tratado de 1904". Foreign Affairs En Español 4 (4), octubre-diciembre. 2004: 94.

Maira, Luis (Chile); Murillo De La Rocha, Javier (Bolivia). El largo conflicto entre Chile y Bolivia. Dos visiones. Santiago de Chile: Aguilar Chilena de Ediciones, 2004.

Mulian, Tomás. Chile actual. Anatomía de un mito. Lom Ediciones, 1997.

Mulian, Tomás. El consumo me consume. Lom Ediciones, 1999.

Milet, Paz Verónica. "Chile-Perú: las dos caras de un espejo". Revista de Ciencia Política XXIV (2). Pontificia Universidad Católica de Chile, 2004.

Rojas, Mauricio. "Chile y la globalización”. En: $<$ www.cadal.org $>$ [Consultado el 18 de noviembre de 2007].

Rosecrance, Richard. The Rise of the Trading State. Basic Books. New York, 1986. Edición en castellano: Madrid. Alianza Editorial, 1986.

Sodupe, Kepa. La teoría de las relaciones internacionales a comienzos del siglo XXI. Guipúzcoa: Servicio Editorial de la Universidad del País Vasco, 2003.

Wendt, Alexander. "Anarchy is what states make of it: the social construction of power politics". International Organization 46. 1992: 391-425. 